\title{
Noise Awareness and Noise Prevention as Strategies for Curtailing the Risk of Noise Induced Hearing Loss among College Students in Osun State, Nigeria
}

\author{
Alawiye Oluwatayo M.
}

\begin{abstract}
Noise induced hearing loss is a consequence of undue exposure to noise and it poses a serious auditory challenges to the affected victim. Hence, this study attempted to examine noise awareness and noise prevention as strategies for curtailing the risk of noise induced hearing loss among college students. One hundred and twenty respondents were sampled randomly from Osun State College of Education, Ila-Orangun, Nigeria. The main instrument for data collection was self designed questionnaire. Three hypotheses were formulated and tested.The data collected were analysed, using Pearson Product Moment Correlation. The findings from the study revealed that there was a significant relationship between noise awareness and the prevention of noise induced hearing loss among college students. Besides, the study revealed a non significant but positive relationship between noise awareness and noise induced hearing loss. The study recommended among others things the need for noise awareness among college students as many of them were ignorant of danger of exposure to excessive noise. It also stressed the need for education and information on availability and use of noise prevention devices so as to be able to checkmate the risk of noise induced hearing loss among students.
\end{abstract}

Index Terms - noise awareness, noise prevention, noise induced hearing loss, college students.

\section{INTRODUCTION}

It is evident in this information age that many people are still ignorant of the evil effects and havoc exposure to noise can inflict on human hearing. No wonder many people engage in activities that make them susceptible to the menace of noise. The advent of modern technological devices have compounded the situation as most of the youths and college students nowadays derive pleasure in using earpiece, head phone, $\mathrm{mp} 3$, amplified music, et cetera that generate uncontrolled noise capable of damaging the hair cells. Taljaard, Leishman and Eikelboom (2013) opined that personal listening devices (PLDs) is a major cause of hearing loss in children and adolescent. Similarly, Henderson, Testa and Hartnick (2011) observed an increase in the exposure to loud noise and music through headphones with reduction in hearing protection use in

Alawiye Oluwatayo M., Dept Of Educational Psychology, Osun State College Of Education, Ila-Orangun, Nigeria. the United States of America. Balanay and Kearney (2015) submitted that college students frequently engage in rock concerts, sporting events and night clubs more than any other events. In most cases, the attendant effect of prolong exposure to noise is noise induced hearing loss. This is because as more sounds are rushing into the ears at louder and uncontrolled volumes, auditory or hearing ability is sure to be damaged. It was observed that rock concerts can generate as much as $110-120 \mathrm{~dB}$ - the same sound intensity can be generated in headsets, amplified music and even in crowdy and noisy classroom environment. Unfortunately, hearing loss does not serve notice, it occurs gradually and it can take length of time before the victims fully aware and at that time, remedy may be impossible. Early detection of hearing loss (temporarry threshold shift is desirable as it would create avenue for prompt treatment and correction. Besides, it would foreclose the possibility of being degenerated into permanent threshold shift (permanent loss) where remedy will be impossible.

Considering the danger inherent in contacting noise induced hearing loss, there is urgent need for noise awareness for all and sundry and most importantly the college students. Students need to be abreast of what constitute noise and which noise can cause damage especially anything above 85 decibels, it menace, how it can be controlled and prevented and possible practical steps to evade the risk of noise induced hearing loss. It is often said that prevention is better than cure. Prevention is imperative because the average healthy and non exposed person can have normal hearing for at least up to age sixty. Besides, it is better not to experience hearing loss than to fall victim and be looking for solution. It is pertinent to state that noise induced hearing loss does not only bring about permanent loss of hearing ability, it also has both psychological and social effects on the affected person. But the consolation is that, although permanent, irreversible and not fully treatable, it is virtually 100 percent preventable. Hence, it is imperative for all college students to be acquainted with possible ways of preventing excessive noise so as to stand clear from its infection. Succintly put, every college student needs adequate knowledge of hearing, varieties of hearing loss and what causes these, how noise affects hearing temporarily and permanently, detection of noise induced hearing loss and prevention strategies for noise 
induced hearing loss (Folmer, and Martin, 2007).

The indiscriminate exposure to noise by college students through many sources underscore their inadequate understanding of evil effect of loud noise or sound capable of causing hearing loss. This ignorance did not allow them to recognise the need for noise prevention, thus making them prone to the risk of noise induced hearing loss. Hence, this study focussed on the topic, "noise awareness and noise prevention as strategies for curtailing the risk of noise induced hearing loss among college students". It is believed that good knowledge of loud noise and its implication on auditory ability coupled with possible prevention mechanism would help a lot to guide against and salvage many students from the risk of noise induiced hearing loss.

\section{LITERATURE REVIEW}

Noise induced hearing loss (NIHL) relates to hearing impairment that results from exposure to loud sound. According to Edward, Manohar, et al (2016) the term noise induced hearing loss refers to reduction in auditory acuity associated with noise exposure . In the perception of Brian and Fligor (2017) noise induced hearing loss is a hearing disorder that is characterized by a gradual, progressive loss of high frequency hearing sensivity over time, as a result of exposure to excessive noise levels. Precisely, when an individual is exposed to loud sounds or noise for a long time, sensitive structures of the inner ear particularly hair cells can damage resulting in noise induced hearing loss. Mill and Henderson (2006) submitted that hearing tend to deteriorate gradually from chronic and repeated noise exposure, such as to loud music or background noise, or suddenly, from exposure to impulse noise (a short high intensity noise), such as a gunshot or airhorn. In both types, loud sound overstimulates delicate hearing cells, leading to the permanent injury or death of the hair cells. Simply put, noise induced hearing loss develops gradually so that the affected individuals may lose a significant amount of hearing before becoming aware of its presence (Brian and Fligor (2017) .

It is pertinent to state that any source of noise can cause hearing loss and that exposure to excessively high decibel (above $85 \mathrm{~dB}$ ) levels from any sound source over time can cause hearing loss. Although, there are limited researches, available ones maintained that increased exposure to loud noise through personal listening devices is a risk factor for noise induced hearing loss (Cone, Wake, and Tobin (2010). Besides, more than half of people are exposed to sound through music exposure on personal devices greater than recommended levels (Jiang, Zhao, Guderley and Manchaiah (2016).) In addition, it is estimated that $15 \%$ of young people are exposed to sufficient leisure noises (i.e. concerts, sporting events, daily activities, personal listening devices, etc.) that are capable of causing noise induced hearing loss (Carter, Williams and Black (2014). Similarly, in United Kingdom, data indicated that $20 \%$ of young people regularly expose themselves to excessive levels of loud music (Shield, 2006). Rawool and Colligon (2008) reported from a survey conducted that college students are most exposed to dangerous noise levels when listening to personal music players, car stereo systems and attending music concerts and night clubs.

A lot of research work has established correlation between exposure to noise and noise induced hearing loss. From the study carried out by Edward, Manohar, et al (2016), it was reported that out 111 workers that were exposed to noise, $51 \%$ had noise induced hearing loss, the average ambient noise being $80.5 \mathrm{~dB}$. In the study of Musiba (2015), the prevalence of noise induced hearing loss was $47 \%$ with $12 \%$ having poor hearing and 35\% mild heaing impairment. Rabinowitz (2015) found out in his study that noise can cause permenent hearing loss at chronic exposures equal to an average SPL of $85 \mathrm{~dB}$ or higher for 8 hour period. Once hearing ability is lost this way, it is always difficult or impossible to restore it in human. Also, researches have provided a lot of evidences that confirmed long term exposure to noise constitutes a health risk and can modify social behaviour, cause annoyance and even propensity for stroke.

It is saddens that, as harmful and injurious excessive exposure to noise is, many parents, young people and college students inclusive are not aware of its implications on their hearing. A study confirmed that $96.3 \%$ of parents did not believe their adolescents were at risk, and only $69 \%$ had talked to their children about hearing protection; those aware of NIHL risks were more likely to talk to their teens (Clark, Davis, Paul, and Singer (2014). In order to create real awareness about harmful noise and possible prevention strategies, the first step is education. Education is a key to prevention. Before hearing protective actions will take place, a person must understand they are at risk for NIHL and be acquainted with possible options for prevention. (Fausti, Wilmington and Helt (2005). Having hearing protection helps to protect ears by reducing noise by $15 \mathrm{~dB}$ to $32 \mathrm{~dB}$ depending on the type of protective devices.

NIHL can be prevented through the use of simple, widely available, and economical tools. This includes but is not limited to personal noise reduction through the use of ear protection (i.e. earplugs and earmuffs), education, and hearing conservation programs. For the average person, there are three basic things that can be kept in mind to reduce NIHL, "walk away, turn it down, protect your ears."(Johnson and Martin 2016).

\section{HYPOTHESES}

Three null hypotheses were drawn for the purpose of this research work and they are stated as follows:

i. There is no significant relationship between noise awareness and noise induced hearing loss among college students.

ii. There is no significant relationship between noise prevention and noise induced hearing loss among college students.

iii. There is no significant relationship between noise awareness and the prevention of noise induced hearing loss among college students.

\section{PURPOSE OF THE STUDY}

The purpose of this research among other things includes: 
i. To examine the relationship between noise awareness and noise induced hearing loss among college students in Osun State;

ii. To examine the relationship between noise prevention and noise induced hearing loss among college students in Osun State;

iii. To examine the relationship betwen noise awareness and noise prevention among college students in Osun State.

\section{RESEARCH DESIGN}

In this research study, descriptive research design was employed. The researcher resolved to embrace this design because he did not manipulate any variable in the study.

\section{POPULATION}

The target population for this study comprised all students in Osun State college of Education, Ila-Orangun, Osun State, Nigeria. The prolific use of earpiece, headphones, exposure and preference for amplified music, unfriendly acoustic and crowdy lecture room, among others make some of the students to be susceptible to the risk of noise induced hearing loss; hence, their choice for this study.

\section{SAMPLE AND SAMPLING TeChNIQUeS}

The sample for this study consisted of 120 respondents selected from Osun State College of Education, Ila-orangun. Besides, simple random sampling technique was adopted in selecting the sample for the study.

\section{INSTRUMENT}

The main instrument employed to collect data for this study was self designed questionnaire tagged 'Noise Awareness and Noise Prevention Inventory' (NANPI). It comprised of two sections A and B. Section A was designed to elicit demographic information while section B comprised of fifteen question items arranged on a likert scale: strongly agreed, agreed, undecided, disagreed and strongly disagreed.

\section{VALIDITY AND RELIABILITY}

The researcher ensured the content and face validity of the instruments used in order to ensure it appropriateness for the study. Besides, Cronbach Alpha was used to determine the reliability coefficient of the instrument which is 0.68 .

\section{Method OF Data ANALYSIS}

In the course of this research work, the researcher employed the use of Pearson Product Moment Correlation to analyse all the collected data.

\section{RESUlTS AND DISCUSSION}

\section{Testing of Hypotheses}

PEARSON CORRELATION OF RELATIONSHIP EXISTING BETWEEN THE VARIABLES

\begin{tabular}{|c|c|c|c|c|}
\hline & & Awareness & Prevention & $\begin{array}{l}\text { Noise } \\
\text { Induced } \\
\text { Hearing } \\
\text { Loss } \\
\end{array}$ \\
\hline \multirow{3}{*}{$\begin{array}{l}\text { Pearson } \\
\text { Correlation }\end{array}$} & Awareness & 1.000 & & \\
\hline & Prevention & 0.215 & 1.000 & \\
\hline & $\begin{array}{l}\text { Noise Induced } \\
\text { Hearing Loss }\end{array}$ & 0.145 & 0.097 & 1.000 \\
\hline \multirow{3}{*}{$\begin{array}{l}\text { Sig. } \\
\text { (2-tailed) }\end{array}$} & Awareness & . & & \\
\hline & Prevention & 0.015 & . & \\
\hline & $\begin{array}{l}\text { Noise Induced } \\
\text { Hearing Loss }\end{array}$ & 0.102 & 0.275 & . \\
\hline \multicolumn{2}{|l|}{$\mathbf{N}$} & 129 & 129 & 129 \\
\hline \multicolumn{2}{|l|}{ Mean } & 3.60 & 3.23 & 1.96 \\
\hline
\end{tabular}

Hypothesis I: There is no significant relationship between noise awareness and noise induced hearing loss among college students.

A Pearson correlation analysis was conducted to examine whether there is a relationship between noise awareness and noise induced hearing loss among the students. The results revealed a non-significant but positive relationship, $\mathrm{r}=0.145, \mathrm{~N}$ $=129, \mathrm{p}(0.102)>0.05$. The correlation was weak in strength. Higher levels of noise awareness among students were associated with low levels of noise induced hearing loss (Table 4.1). The null hypothesis is therefore accepted. Awareness about danger of indiscriminate exposure to loud noise or sound ought to produce reduction in the incidence of noise induced hearing loss. The variation in this finding was due to non awareness of many college students about evil effects of noise and those that were even aware believed thay were not susceptible to noise induced hearing loss. The finding of Casey (2017) confirmed the foreging as he reported that hearing conservation programmes and initiatives have not worked because college students believed thay are not susceptible to noise induced hearing loss.

Besides, according to him, data suggested that average college students know very little about the prevalence of noise induced hearing loss and its implications, hence, they relate to noise levels in the environment everyday. In the same vein, the study of Edward and Manohar (2016) also supported the present finding as they reported that out of 111 industrial workers, none of them was aware that noise causes hearing loss, yet, many of them are prone to the risk. Similarly, from the study of Chung, Roches, et al (2005), it was found out that only $8 \%$ of participants labeled noise induced hearing loss as "a very big problem". Thus, it can be concluded that college students are grossly unaware of dangerous effects of noise induced hearing loss.

Hypothesis II:There is no significant relationship between noise prevention and noise induced hearing loss among college 
students.

Table 4.1 shows the results of a Pearson correlation analysis conducted to examine whether there is a relationship between noise prevention and noise induced hearing loss among college students. An insignificant but positive relationship was revealed, $\mathrm{r}=0.097, \mathrm{~N}=129, \mathrm{p}(0.275)>0.05$. The correlation was weak in strength, indicating that higher levels of noise prevention was associated with lower levels of noise induced hearing loss. Hence, the null hypothesis is accepted. In actual fact, noise prevention is capable of reducing the incidence of noise induced hearing noise. The variation in this study was due partly to the fact that many college students are not aware of existence of noise prevention devices, their mode of operations and effectiveness.

Gagne, Southall and Jennings (2011) reported from their studies that some students that are susceptible to the risk of noise induced hearing loss refused to use noise prevention devices or hearing protection devices due to unregulated noise pollution, stigmatisation, public embarrassment or shame and feeling of being the odd one out of the crowd. Besides, Osisanya and Odili (2015) found out that many tertiary institutions in Nigeria are not acoustically suitable for the use of hearing protection devices, thus making the devices unfriendly to the users. From the study conducted by Alawiye (2017), it was discovered that many college students lack awareness about availability and use of noise prevention devices as many of them did not use nor acquaint with funtions of hearing protection devices. Further, over reliance on hearing protectors alone to reduce the risk of noise exposure might not be an appropriate strategy due to the fact that hearing protection devices is often ignored in tropical countries because of the hot and humid climate conditions which the use of this device impractical (Gomes, Lloyd and Norman, 2002).

Hypothesis III: There is no significant relationship between noise awareness and prevention of noise induced hearing loss among college students.

Table 4.1 shows the results of a Pearson correlation analysis conducted to examine whether there is a relationship between noise awareness and prevention of noise induced hearing loss among college students. A significant and positive relationship was revealed, $\mathrm{r}=0.215, \mathrm{~N}=129, \mathrm{p}(0.015)<0.05$. The correlation was strong, indicating that higher levels of noise awareness were associated with higher levels of noise prevention. Hence, the null hypothesis is rejected. Actually, there is a strong connection between noise awareness and the prevention of noise induced hearing loss. This was confirmed by the findings of Taljaard, Leishman and Eikelboom (2013) as they reported a significant relationship between noise awareness and the prevention of noise induced hearing loss. Further, Fausti, Wilmington and Helt (2005) reported from their studies that noise awareness often results in the reduction and prevention of noise induced hearing loss.

\section{CONCLUSION}

Realising the challenges posed by noise induced hearing noise, it is not desirable by all categories of human being whether old or young, students or non students, educated or illiterate. Hence, there is need for concerted efforts to checkmate its occurrence and prevalence by every possible means. Wellness of hearing is indispensable for effective functioning as human beings and for meaningful participation and contribution to the social and economic life in the society. College students deserve to be duly informed or educated about noise, its menace and prevention.

\section{RECOMMENDATION}

It has been revealed that noise awareness could result in the prevention of noise induced hearing loss; hence, there is imperativeness to promote the level of awareness among college students. No wonder, it was said that education is the key, hence, students need to be educated about danger inherent in undue addiction to amplified music, rock concert, noisy party, et cetera. They need to be informed about the availability of hearing protection devices in the market, their functions, usefulness and maintenance. They need to be told about dangerous decibel $(\mathrm{dB})$ which is injurious to man's hearing (anything above $85 \mathrm{~dB}$ is becoming abnormal and dangerous). They need information about symptoms of noise induced hearing loss: ringing in the ears, difficulty in understanding speech, fullness in the ear, pains in the ear, etc. Places and professionals they can consult like audiologist, otologist, otolaryngologist, etc. In case they find themselves in an unduly noisy environment where the sound there is unbearable or intolerable, they need to be taught possible preventive mechanism like the use of ear protection, disposable plugs, sound isolating earphones, special purpose headsets, reusable earplugs, ear muffs, placing a barrier, etc. Students that delight in listening to music continuously should be encouraged to reduce the listening time and always remember to turn down the volume. The classroom or lecture room should be made to be acoustically friendly and conducive. The cost of ear protective devices should be subsidised to make it affordable by average students. Periodic screening should be organised for students so as to be able to identify those that are prone to the risk of hearing loss. In summary, hearing conservation programme should be introduced and implemented in tertiary institutions of learning.

\section{REFERENCES}

[1]Brian, J., and Fligor, S.D. (2017). Noise induced hearing loss. Boston, Havard Medical School.

[2]Carter, L.,Williams, W. and Black, A. (2014). "The leisure-noise dilemma: hearing loss or hearsay? What does the literature tell us?". Ear and Hearing. 35 (5): 491-505. https://doi.org/10.1097/01.aud.0000451498.92871.20

[3]Chung, J.H., Roches, D., Meunier, J., and Eavey, R.D. (2005). Evaluation of Noise induced hearing loss in young people using a web based technique. Pediatrics, 115:4, 861-867 https://doi.org/10.1542/peds.2004-0173

[4]Clark, S. J., Davis, M. M., Paul, I. M., and Singer, D. C. (2014). "Parental perspectives on adolescent hearing loss risk and prevention". JAMA Otolaryngology-Head and Neck Surgery. 140 (1): 22-28. https://doi.org/10.1001/jamaoto.2013.5760

[5]Cone, B.K., Wake, M. and Tobin, S. (2010). "Slight-mild sensorineural hearing loss in children: audiometric, clinical, and risk factor profiles". Ear Hear. 31 (2): 202-212.

https://doi.org/10.1097/AUD.0b013e3181c62263 
[6]Curran, C. (2017) "Can you hear me? Assessing College Students Knowledge of noise induced hearing loss. Honors Theses. 14. Retrieved September $\quad 10, \quad 2017 \quad$ from http://digitalcommons.assumption.edu/honorstheses/14

[7]Edward, M., Manohar, S., Somayaji, G., and Kallikkadan, H. (2016). Prevalence, awareness and preventive practices of noise induced hearing loss in a plywood industry. Indian journal of Otorlogy, 22: 14-18 https://doi.org/10.4103/0971-7749.176569

[8]Fausti, S.A.; Wilmington, D.J., Helt, P.V. and Helt, W.J. (2005). "Hearing health andcare: The need for improved hearing loss prevention and hearing conservation practices". Journal of Rehabilitation Research and Development. 42: 45-62. https://doi.org/10.1682/JRRD.2005.02.0039

[9]Fligor, B. (2013). Acceptable strategies for prevention of noise- and music-induced hearing loss. Audiology Online, Article 12205. Retrieved September 10, 2018 from: http://www.audiologyonline.com

[10] Folmer, R.L. and Martin, W.H. (2007). Effectiveness of dangerous decibel, a based hearing loss prevention programme. Annual Journal of Audiology;16:165-81 https://doi.org/10.1044/1059-0889(2007/021)

[11] Gomes, J., Lioyd, O. and Norman, N. (2002). The health of the workers in a rapidly developing country: effects of occupation. Occupational Medicine, 52:121-128 https://doi.org/10.1093/occmed/52.3.121

[12] Henderson, E,, Testa, M.A. and Hartnick, C. (2011). Prevalence of noise induced hearing-threshold shifts and hearing loss among United States youths. Pediatrics; 127. https://doi.org/10.1542/peds.2010-0926

[13] Jiang, W., Zhao, F., Guderley, N. and Manchaiah, V. (2016). "Daily music exposure dose and hearing problems using personal listening devices in adolescents and young adults: A systematic review". International Journal of Audiology. 55 (4): 197-205. https://doi.org/10.3109/14992027.2015.1122237

[14] Johnson, M. And Martin, W.H.(2015)."Dangerous decibels educator guide"Dangerous Decibels. Oregon Health and Science University

[15] Mills, J.H. and Henderson, M.S.(2006). Noise-induced hearing loss. New York: Raven. pp. 41-68.

[16] Musiba, Z. (2015). The prevalence of noise induced hearing loss among Tanzanian miners. Occupational Medicine; 65: 386-390 https://doi.org/10.1093/occmed/kqv046

[17] Osisanya, A. And Odili, J. N. (2015). Psychological factors as determinant of use and adjustment to assistive technology by students with hearing impairment in tertiary institution in Oyo State, Nigeria. Journal of Special Education, 13:1,45-58

[18] Rabinowitz, P. (2015). Noise induced hearing loss - American family physician.Retrieved September 4, 2018 from http://www.aafp.org/afp/2000/0501/p2749.html

[19] Rawool,V. and Colgon, W. (2008). "Auditory lifestyles and beliefs related to hearing loss among college students in the USA. Noise and Health, 10:38 https://doi.org/10.4103/1463-1741.39002

[20] Shield, B. (2006). Evaluation of social and economic costs of hearing impairment. A report for Hear-it, 2006. Retrieved on September 10, 2018 from http://www.german.hearit.org/multimedia/Hear_It_Report

[21] Taljaard, D.S., Leishman, N.F. and Eikelboom, R.H. (2013). Personal listening devices and the prevention of noise induced hearing loss in children: The cheers for ears pilot programme. Noise Health; 15:261-8 https://doi.org/10.4103/1463-1741.113523 